\title{
Metal-resin Composite Restorative Material using Powder-liquid System
}

\author{
Somchai URAPEPON and Hideo OGURA \\ Developmental Science of Oral Biomaterials, \\ The Nippon Dental University Graduate School at Niigata \\ 1-8 Hamaura-cho, Niigata, 951-8580, Japan
}

Received April 15, 1999/Accepted June 9, 1999

\begin{abstract}
In order to further improve the mechanical properties of a metal-resin composite and avoid the problems which were found in the previous metal-resin composite using a 2-paste system, another type of metal-resin composite using a powder-liquid system was developed. In the new system 4-META treatment was carried out at low temperature and DMPT was separated from the 4-META treated particles. The efficacy of this system as well as the effects of 4-META concentration, duration of 4-META treatment (immersion time) and filler content on the flexural properties, working time and setting time were investigated. The flexural strength of the powder-liquid composite was significantly affected by two main factors, immersion time and filler content, and the other properties (flexural modulus, working time and setting time) were by all three main factors. The highest flexural strength of the prepared composite was 91.8 $\mathrm{MPa}$, which was higher than that of the 2-paste composite $(64.0 \mathrm{MPa})$ by about $43 \%$. This was achieved at a 0.1 ratio of 4-META concentration, $30 \mathrm{~s}$ immersion time and 94 mass\% filler content. The working time and setting time ranged between 2.3-13.6 $\mathrm{min}$ and 4.2-20.1 $\mathrm{min}$, respectively, and those of the highest strength composite were 3.0 and 5.2, respectively. The results of the present study indicate that the powder-liquid system is effective to improve the properties of the metal-resin composite.
\end{abstract}

Key words: Silver alloy, Dental composite, 4-META

\section{INTRODUCTION}

Direct restorative materials containing metal particles as the filler have been experimentally prepared by several researchers. Hirano et al. ${ }^{1,2)}$ used stainless steel particles as the filler to prepare a composite for magnetic cores of fixed prostheses. Kakuta et $a l . .^{3)}$ used $70 \% \mathrm{Ag}-27 \% \mathrm{Sn}-3 \% \mathrm{Cu}$ alloy particles as the filler to prepare a posterior composite, aiming to improve the wear resistance and durability. Following this study, Urapepon et $a l_{.}{ }^{4)}$ found that the flexural strength of this composite was improved by enhancing the bond between 4-(2-methacryloyloxyethoxycarbonyl) phthalic anhydride (4-META) and the filler particles using acid- and heat-treatments. Although the maximum flexural strength of these metal-resin composites was close to $80 \mathrm{MPa}\left(76.0 \mathrm{MPa}\right.$ for stainless steel filled composite ${ }^{2)}$ and $77.6 \mathrm{MPa}$ for Ag-Sn filled composite $^{4)}$ ), this may not be sufficient for posterior tooth application ${ }^{5)}$, such as occlusal restorations and fixed prosthodontic cores.

In the previous study for Ag-Sn filled composite by Urapepon et $a l^{4)}$, reactivity of the alloy particles was occasionally observed. Miyagawa et al. ${ }^{6,7)}$ further studied 
this reactivity and reported that the polymerization of urethane dimethacrylate (UDMA) containing benzoyl peroxide (BPO) was induced by Ag-Sn particles treated with 4-META without tertiary amine. This result suggests that the UDMA in the previous metal-resin composite underwent some polymerization after the preparation of the paste, which may be related to the inadequate strength of the previously reported composite. This problem could be avoided by separation of the UDMA monomer from the 4-META treated particles and BPO. In addition to the reactivity of the alloy particles, another factor might have adversely affected the strength of the metal-resin composite. It has been reported that a chemical reaction can be induced between phthalic anhydride group and amine compounds ${ }^{8)}$. Since 4-META has the phthalic anhydride group in its structure, it is likely that some part of N, N-dimethylp-toluidine (DMPT) in the catalyst paste dissolved in 4-META before mixing with the base paste containing BPO. This reaction may be avoided by the separation of 4META from DMPT.

Based on the above points, a new system consisting of powder and liquid (powder-liquid system) is proposed to ameliorate the problems of the metal-resin composite containing of Ag-Sn particles as the filler, and to improve its mechanical properties. In the powder-liquid system, the powder component is $\mathrm{Ag}-\mathrm{Sn}$ particles treated with 4-META and BPO. The temperature of 4-META treatment, in this system, is lower than that in the previous studies ${ }^{3,4)}$ in order to prevent the decomposition of BPO. The liquid component is UDMA monomer containing DMPT. This system may be effective in minimizing both the early polymerization of UDMA and the reaction between 4-META and DMPT, and thus an improvement in the strength of the metal-resin composite can be expected.

The purpose of the present study was to experimentally prepare a metal-resin composite using the powder-liquid system (powder-liquid composite) under different conditions of 4-META concentration, treatment time and filler content, and to investigate the efficacy of this system as well as the effect of different conditions on some properties.

\section{MATERIALS AND METHODS}

\section{Preparation of powder-liquid composite}

The materials used in the present study are listed in Table 1.

$\mathrm{Ag}-\mathrm{Sn}$ spherical alloy particles (73.2 mass\% $\mathrm{Ag}, 26.8$ mass $\% \mathrm{Sn}$ ) were produced by the research unit, Faculty of Dentistry, Mahidol University, Thailand, using an atomization method. Three particle sizes of the alloy, under $38 \mu \mathrm{m}, 38-45 \mu \mathrm{m}$ and $45-53$ $\mu \mathrm{m}$ were combined at the ratio of $3: 1: 1$ by mass, respectively and utilized for the filler of a metal-resin composite. The powder part of the composite was prepared using these particles. The particles were treated with both 4-META and BPO. For this purpose, 4-META acetone solution was prepared at two different concentration ratios $(1: 10=0.1$ and $2: 10=0.2$ by mass) of 4 -META to acetone (JIS K $8034 \mathrm{~S}$, Lot no. KCJ 7772, Wako pure chemical industrials Ltd. Osaka, Japan). BPO as an 
Table 1 Materials used in this study

\begin{tabular}{|c|c|c|c|}
\hline & Materials & Code & Batch No. \\
\hline Metal filler & Ag-Sn alloy particle ${ }^{1}$ & AS750 & $9801 \mathrm{AS} 750$ \\
\hline Coupling agent & $\begin{array}{l}\text { 4-(2-Methacryloyloxyethoxycarbonyl) phthalic anhy- } \\
\text { dride }^{2} \text { (crystal form) }\end{array}$ & 4-META & 97001 \\
\hline Monomers & $\begin{array}{l}\text { 1,6-Bis (methacryloyloxy-2-ethoxycarbonyl-amino)- } \\
2,4,4(2,2,4) \text {-trimethylhexane }{ }^{3} \\
\text { Triethylene glycol dimethacrylate }\end{array}$ & $\begin{array}{l}\text { UDMA } \\
\text { TEGDMA }\end{array}$ & $\begin{array}{l}050155 \\
1104 \mathrm{~S}\end{array}$ \\
\hline Redox initiator & $\begin{array}{l}\text { Benzoyl peroxide }{ }^{5} \text { (crystal form) } \\
N, \text { N-dimethyl-p-toluidine }{ }^{6}\end{array}$ & $\begin{array}{l}\text { BPO } \\
\text { DMPT }\end{array}$ & $\begin{array}{l}\text { M6K9289 } \\
\text { GA01 }\end{array}$ \\
\hline Inhibitor & Hydroquinone monoethyl ether ${ }^{7}$ & $\mathrm{MEHQ}$ & PAM0168 \\
\hline $\begin{array}{l}{ }^{1} \text { Mahidol Uni } \\
{ }^{2} \text { Sun Medical, } \\
{ }^{3} \text { Negami Kog: } \\
{ }^{4} \text { Shin Nakamı } \\
{ }^{5} \text { Nacalai Tesq } \\
{ }^{6} \text { Tokyo Kasei } \\
{ }^{7} \text { Wako pure cl }\end{array}$ & $\begin{array}{l}\text { versity, Bangkok, Thailand } \\
\text { Osaka, Japan } \\
\text { yo, Negami, Japan } \\
\text { ura Kagaku Kogyo, Osaka, Japan } \\
\text { yue Inc, Kyoto, Japan } \\
\text { Kogyo, Tokyo, Japan } \\
\text { hemical industries, Osaka, Japan }\end{array}$ & & \\
\hline
\end{tabular}

initiator was then dissolved into the solution at 1 mass \%. The alloy particles were immersed in the prepared solutions at $23 \pm 2{ }^{\circ} \mathrm{C}$ and stirred using a stainless steel spatula for $30 \mathrm{~s}$. The particles were left in the solution for $30 \mathrm{~s}, 2 \mathrm{~h}$ or $4 \mathrm{~h}$, and then dried in the oven at $40^{\circ} \mathrm{C}$ for $3 \mathrm{~min}$. The liquid component of the system was prepared from a monomer consisting of urethane dimethacrylate (UDMA, 75 mass\%) with triethylene glycol dimethacrylate (TEGDMA, 25 mass\%) as the resin matrix. DMPT was added to the monomer at 0.25 mass $\%$. Using the prepared powder and liquid, a flexural test and measurements of working time, setting time and temperature rise during the setting of the composite were carried out.

\section{Flexural test}

The specimens for the flexural test were prepared following the ISO $4049: 1988$ for resin-based filling materials. The treated particles were mixed with the resin monomer containing DMPT for $30 \mathrm{~s}$, either at 93,94 or 95 mass $\%$ of the filler content. The mixture was filled in a $25 \times 2 \times 2 \mathrm{~mm}$ PTFE-coated stainless steel mold placed on a glass plate, using a syringe ( $C-R$ Syringe, Centrix Co. CT, USA). After the filling of the mixture, another glass plate was applied on top of the mold to remove excess material from the mold. The specimen assembly was held together by a C-clamp and immersed in $37 \pm 1{ }^{\circ} \mathrm{C}$ distilled water. The metal-resin composite specimen was carefully removed from the mold at 15 min after the start of mixing and then stored in distilled water at $37 \pm 1^{\circ} \mathrm{C}$ for $24 \mathrm{~h}$. After $24 \mathrm{~h}$ storage, the specimen was polished using \# $1500 \mathrm{SiC}$ paper, and the dimensions were measured before testing. Four specimens were prepared for each of the 18 conditions which were the combinations of two concentration ratios of 4-META, three different immersion times and three contents of the filler particles. These experimental factors and levels are listed in Table 2. A 
Table 2 The experimental factors and levels

For flexural strength, flexural modulus, working time, setting time and temperature rise

\begin{tabular}{lccc}
\hline Factors & Level 1 & Level 2 & Level 3 \\
\hline A: 4-META concentration ratio & 0.1 & 0.2 & - \\
B: Immersion time & $30 \mathrm{~s}$ & $2 \mathrm{~h}$ & $4 \mathrm{~h}$ \\
C: Filler content & 93 mass\% & 94 mass $\%$ & 95 mass $\%$ \\
\hline
\end{tabular}

For percent elution

\begin{tabular}{lccc}
\hline Factors & Level 1 & Level 2 & Level 3 \\
\hline A: Immersion time & $30 \mathrm{~s}$ & $2 \mathrm{~h}$ & $4 \mathrm{~h}$ \\
B: Filler content & 94 mass $\%$ & 95 mass $\%$ & - \\
\hline
\end{tabular}

three-point flexural test was carried out using a universal testing machine (Autograph DSS-5000, Shimadzu Ltd., Kyoto, Japan) at a cross-head speed of $1 \mathrm{~mm} / \mathrm{min}$. The flexural strength and the modulus of elasticity were calculated.

The former metal-resin composite using the 2-paste system (2-paste composite) was also prepared, following the previous study ${ }^{3)}$ at the highest strength condition (2.5\% 4-META concentration and $93 \%$ filler contents), and its flexural properties were also measured for comparison with those of the powder-liquid composite.

The fractured surfaces of the prepared composites after the flexural test were observed under a scanning electron microscope (JSM-T20, JEOL Co.Ltd, Tokyo, Japan) at $19 \mathrm{kV}$ of acceleration voltage.

\section{Measurement of working time, setting time and temperature rise}

The working time, setting time and temperature rise after mixing the powder and liquid were determined following the ISO 4049:1988 for resin-based filling materials using a thermocouple apparatus. The apparatus was placed in the closed polystyrene box for maximum temperature stability at $23 \pm 1^{\circ} \mathrm{C}$, and connected to a chart recorder (LR4210, Yokogawa electric works Ltd., Tokyo, Japan). The treated particles were hand-mixed with the resin monomer containing DMPT for $30 \mathrm{~s}$. The mixture was filled in a mold in the thermocouple apparatus and the temperature of the material was continuously recorded until the peak temperature was passed. The working time, setting time and temperature rise were determined from the recorded chart as described in ISO $4049: 1988$. Three replications were made for each of the 18 conditions which were the combinations of two concentration ratios of 4-META, three different immersion times and three contents of the filler particles (Table 2). As well as the flexural properties, the working time, setting time and temperature rise of the 2-paste composite were measured in order to compare with the powder-liquid composites.

\section{Measurement of elution of leachable component}

The specimens were prepared using the same procedure as described for the flexural 
specimen preparation at 0.1 ratio of 4 -META concentration, for $30 \mathrm{~s}, 2 \mathrm{~h}$ or $4 \mathrm{~h}$ of immersion time, and $94 \%$ or $95 \%$ filler content. Specimens of the 2-paste composite were also prepared, following the previous study ${ }^{3)}$. The flexural test was carried out for each specimen. After the flexural tests, all fractured specimens were ground with a pestle and mortar by hand. The ground composites were weighed on an analytical balance to the nearest $0.00002 \mathrm{~g}(\mathrm{CW})$.

After the mass measurement, the leachable component of the resin matrix in the ground composite was extracted using a Soxhlet extractor apparatus. The ground composite was put in a filter paper tube (Thimble filter advantec, Toyo Rocho Kaicha, Ltd., Tokyo, Japan), which was then placed in the lower part of the apparatus. A $100 \mathrm{ml}$ volume of acetone was used as the solvent for the extraction. Hydroquinone monoethyl ether (MEHQ, $250 \mathrm{ppm}$ ) was added to the acetone to prevent polymerization of the extracted monomer in the solution. The extraction was carried out at $80^{\circ} \mathrm{C}$ for 20 cycles. After the extraction, the ground composites and filter paper were removed from the apparatus and dried in an oven at $40^{\circ} \mathrm{C}$ for $24 \mathrm{~h}$, and the mass of the dried composite was measured (DW). The percentage of elution of leachable component from the composite (percent elution) was calculated using the following equation;

$$
\mathrm{PE}=\frac{\mathrm{CW}-\mathrm{DW}}{\mathrm{IW}} \times 100 \cdots \cdots(1)
$$

where PE: percent elution (\%)

CW: total mass of the ground composite $(\mathrm{g})$

DW: total mass of the composite after extraction $(\mathrm{g})$

IW: calculated resin mass of the ground composite $(\mathrm{g})$, which was calculated from the following equation;

$$
\mathrm{IW}=\frac{\mathrm{CW} \times(100-\mathrm{FC})}{100} \cdots \cdots(2)
$$

where FC: filler content (mass\%)

The extraction and the mass measurement were carried out for three specimens in each condition (Table 2).

\section{Statistical analysis of data}

A one-way analysis of variance and a Tukey's multiple comparison test were used to statistically compare the evaluated properties between the powder-liquid composite and 2-paste composite. The effects of three factors, which were the 4-META concentration ratio, immersion time and the filler content, on the properties were analyzed using a three-way analysis of variance and Tukey's interval.

The data were analyzed using two-way ANOVA to determine the effect of the immersion time and filler contents on the percent elution, and one-way ANOVA with Tukey's multiple comparison test to compare the powder-liquid composite and 2-paste 
composite.

Correlation among six properties, which were flexural strength, flexural modulus, working time, setting time, temperature rise and percent elution were statistically analyzed.

\section{RESULTS}

The results of ANOVA and the mean values for flexural strength, flexural modulus, working time, setting time and temperature rise are summarized in Tables 3 and 4, respectively. In Table 4, Tukey's intervals are included to compare the mean values.

Table 3 Summary of the results of one-way and three-way ANOVA for flexural strength, flexural modulus, working time, setting time and temperature rise of the experimental composite

\begin{tabular}{c|l|l|c|c|c} 
Factors & \multicolumn{1}{|c|}{$\begin{array}{c}\text { Flexural } \\
\text { strength }\end{array}$} & $\begin{array}{c}\text { Flexural } \\
\text { modulus }\end{array}$ & $\begin{array}{c}\text { Working } \\
\text { time }\end{array}$ & $\begin{array}{c}\text { Setting } \\
\text { time }\end{array}$ & $\begin{array}{c}\text { Temperature } \\
\text { rise }\end{array}$ \\
\hline $\begin{array}{c}\text { One-Way ANOVA } \\
\text { Different composites }\end{array}$ & $4.50(<0.01)^{* *}$ & $5.54(<0.01)^{* *}$ & $49.43(<0.01)^{* *}$ & $59.06(<0.01)^{* *}$ & $13.32(<0.01)^{* *}$ \\
\hline Three-Way ANOVA & & & & & \\
A (4-META conc.) & $1.09(0.30)$ & $29.17(<0.01)^{* *}$ & $527.19(<0.01)^{* *}$ & $646.78(<0.01)^{* *}$ & $101.28(<0.01)^{* *}$ \\
B (Immersion time) & $6.88(<0.01)^{* *}$ & $10.39(<0.01)^{* *}$ & $12.23(<0.01)^{* *}$ & $8.11(<0.01)^{* *}$ & $2.47(0.10)$ \\
C (Filler content) & $7.73(<0.01)^{* *}$ & $6.45(<0.01)^{* *}$ & $106.45(<0.01)^{* *}$ & $135.13(<0.01)^{* *}$ & $48.75(<0.01)^{* *}$ \\
A $\times$ B & $2.20(0.12)$ & $0.56(0.58)$ & $5.15(0.01)^{*}$ & $3.33(0.047)^{*}$ & $1.10(0.34)$ \\
A $\times$ C & $2.15(0.13)$ & $0.23(0.79)$ & $18.84(<0.01)^{* *}$ & $19.90(<0.01)^{* *}$ & $2.42(0.10)$ \\
B $\times$ C & $0.39(0.82)$ & $2.34(0.07)$ & $0.52(0.72)$ & $0.35(0.84)$ & $0.36(0.83)$ \\
A $\times$ B $\times$ C & $0.35(0.84)$ & $2.33(0.07)$ & $0.46(0.76)$ & $0.49(0.74)$ & $0.71(0.59)$ \\
\hline
\end{tabular}

The numbers are $F$ value, and $P$ value in parenthesis

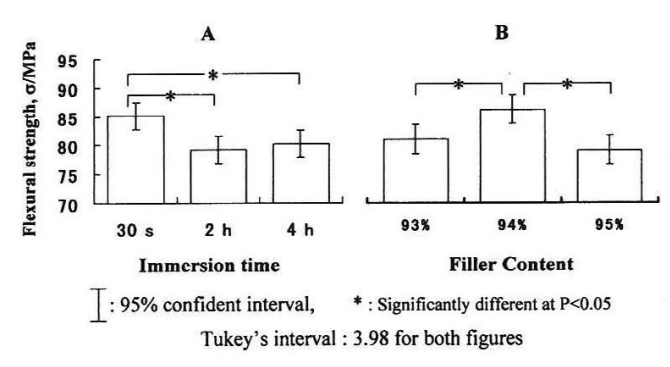

Fig. 1 Flexural strength of the powderliquid composite, at different immersion times $(\Lambda)$ and by different filler contents (B).

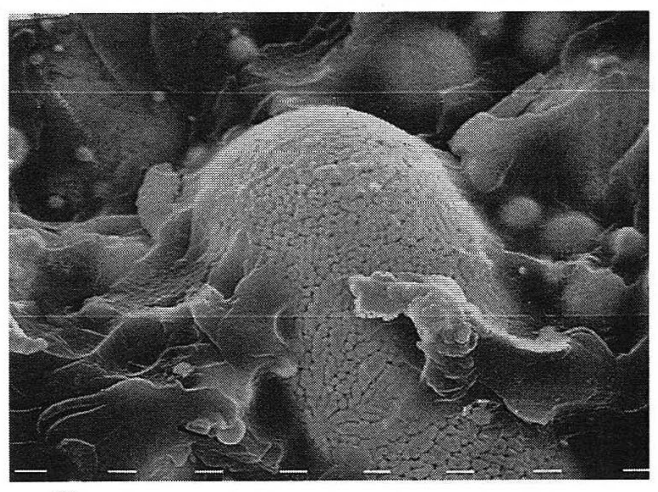

$\stackrel{10 \mu \mathrm{m}}{\longleftrightarrow}$

Fig. 2 Fractured surface of the powderliquid composite specimen. 
Table 4 The flexural strength, flexural modulus, working time, setting time and temperature rise of the powder-liquid composite and former 2-paste composite

\begin{tabular}{|c|c|c|c|c|c|c|c|}
\hline \multirow{2}{*}{\multicolumn{3}{|c|}{ Condition }} & \multicolumn{5}{|c|}{ Mean } \\
\hline & & & $\begin{array}{l}\text { Flexural strength } \\
\qquad(\mathrm{MPa})\end{array}$ & $\begin{array}{c}\text { Flexural modulus } \\
(\mathrm{GPa})\end{array}$ & $\begin{array}{l}\text { Working Time } \\
\quad(\min )\end{array}$ & $\begin{array}{l}\text { Setting Time } \\
(\min )\end{array}$ & $\begin{array}{c}\text { Temperature rise } \\
\left({ }^{\circ} \mathrm{C}\right)\end{array}$ \\
\hline 2-pas & ste comp & osite & $64.00^{*}(2.68)$ & $11.90^{*}(0.74)$ & $9.30^{*}(0.26)$ & $13.43^{*}(0.06)$ & $1.00^{*}(0.10)$ \\
\hline \multicolumn{3}{|c|}{ Powder-liquid composite } & & & & & \\
\hline $\begin{array}{l}\text { 4-META } \\
\text { conc. }\end{array}$ & $\begin{array}{c}\text { Immersion } \\
\text { time }\end{array}$ & \begin{tabular}{|c|}
$\begin{array}{c}\text { Filler } \\
\text { content }\end{array}$ \\
\end{tabular} & & & & & \\
\hline 0.1 & $30 \mathrm{~s}$ & $\begin{array}{l}93 \% \\
94 \% \\
95 \% \\
93 \% \\
94 \% \\
95 \% \\
93 \% \\
94 \% \\
95 \%\end{array}$ & $\begin{array}{ll}87.59 & (3.48) \\
91.83 & (4.66) \\
83.09 & (4.97) \\
79.54 & (5.77) \\
85.83 & (2.40) \\
74.69^{*} & (9.88) \\
79.91 & (3.10) \\
83.62 & (5.43) \\
74.74^{*} & (5.06)\end{array}$ & $\begin{array}{ll}16.10 & (1.38) \\
16.61 & (0.88) \\
17.63 & (2.05) \\
13.93^{*} & (1.34) \\
15.60 & (1.14) \\
15.13^{*} & (0.22) \\
13.84^{*} & (0.72) \\
14.94^{*} & (1.30) \\
15.55^{*} & (1.55)\end{array}$ & $\begin{array}{ll}2.33 & (0.43) \\
3.03 & (0.26) \\
4.50 & (0.72) \\
2.60 & (0.17) \\
3.48 & (0.23) \\
5.65 & (0.61) \\
2.45 & (0.13) \\
3.08 & (0.28) \\
4.70 & (0.92)\end{array}$ & $\begin{array}{ll}4.23 & (0.14) \\
5.22 & (0.45) \\
7.85 & (1.40) \\
4.42 & (0.16) \\
5.63 & (0.32) \\
8.97 & (0.59) \\
4.25 & (0.05) \\
4.95 & (0.38) \\
7.60 & (1.15)\end{array}$ & $\begin{array}{ll}2.35 & (0.15) \\
2.13 & (0.20) \\
1.33^{*} & (0.49) \\
2.28 & (0.20) \\
1.90 & (0.09) \\
1.27^{*} & (0.40) \\
2.68 & (0.24) \\
2.15 & (0.09) \\
1.60^{*} & (0.26)\end{array}$ \\
\hline 0.2 & $30 \mathrm{~s}$ & $\begin{array}{l}93 \% \\
94 \% \\
95 \% \\
93 \% \\
94 \% \\
95 \% \\
93 \% \\
94 \% \\
95 \% \\
\end{array}$ & \begin{tabular}{|ll}
80.94 & $(9.69)$ \\
84.11 & $(4.93)$ \\
82.96 & $(5.13)$ \\
79.44 & $(9.80)$ \\
81.33 & $(6.14)$ \\
$74.83^{*}$ & $(3.04)$ \\
$78.19^{*}$ & $(4.22)$ \\
84.10 & $(4.09)$ \\
80.74 & $(2.20)$ \\
\end{tabular} & $\begin{array}{|ll|}12.88^{*} & (2.32) \\
14.17^{*} & (1.25) \\
16.54 & (0.90) \\
12.71^{*} & (1.78) \\
13.02^{*} & (0.94) \\
13.19^{*} & (0.38) \\
12.70^{*} & (2.22) \\
15.31^{*} & (2.17) \\
12.20^{*} & (1.25) \\
\end{array}$ & $\begin{array}{cc}5.40 & (1.06) \\
7.07^{*} & (1.00) \\
10.93^{*} & (1.10) \\
7.87^{*} & (0.65) \\
8.83^{*} & (1.52) \\
13.60 & (1.22) \\
7.30^{*} & (1.61) \\
7.90^{*} & (0.95) \\
13.53 & (1.17) \\
\end{array}$ & \begin{tabular}{|cc}
8.90 & $(1.56)$ \\
$11.23^{*}$ & $(1.50)$ \\
18.30 & $(2.00)$ \\
$12.03^{*}$ & $(0.06)$ \\
$13.97^{*}$ & $(2.31)$ \\
20.07 & $(0.12)$ \\
$11.17^{*}$ & $(2.10)$ \\
$11.90^{*}$ & $(1.22)$ \\
19.07 & $(1.01)$ \\
\end{tabular} & $\begin{array}{l}1.65^{*}(0.36) \\
1.03^{*}(0.51) \\
0.99^{*}(0.14) \\
1.48^{*}(0.28) \\
1.28^{*}(0.23) \\
0.82^{*}(0.03) \\
1.73^{*}(0.25) \\
1.20^{*}(0.18) \\
0.85^{*}(0.13)\end{array}$ \\
\hline \multicolumn{3}{|c|}{$\begin{array}{c}\text { Tukey's Interval } \\
\text { for one-way ANOVA }\end{array}$} & 14.64 & 3.70 & 2.70 & 3.54 & 0.81 \\
\hline
\end{tabular}

$\mathrm{SD}$ in parentheses

Data with superscript* are not statistically different from 2-paste composite at $p=0.05$ using Tukey's test

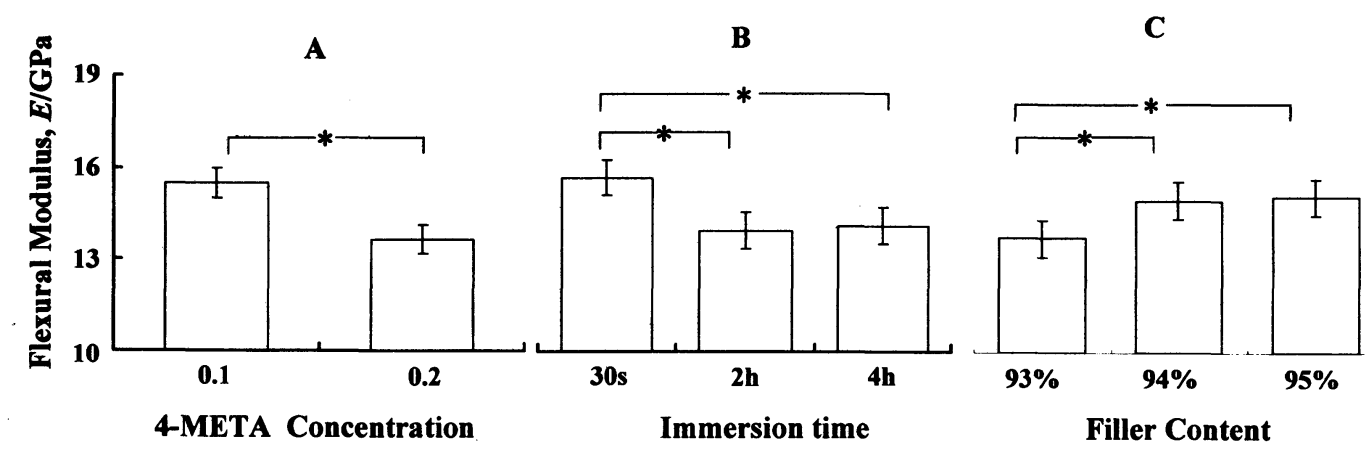

I: $95 \%$ confident interval, $*$ : Significantly different at $\mathrm{P}<0.05$

Tukey's interval : 0.69 for 4-META concentration, 1.01 for immersion time and filler content

Fig. 3 Flexural modulus of the powder-liquid composite, at different 4-META concentrations (A), different immersion times (B) and different filler contents (C). 
The flexural strength of the experimental metal-resin composites using the powder-liquid system ranged from 74.7 to $91.8 \mathrm{MPa}$, whereas that of the 2-paste composite was $64.0 \mathrm{MPa}$. 14 of the 18 powder-liquid composites had significantly higher flexural strength than the 2-paste composite, and the highest strength was obtained at the 0.1 ratio of 4-META concentration, with $30 \mathrm{~s}$ immersion time and $94 \%$ filler content. This was greater than that of the 2-paste composite by about $43 \%$. The immersion time and filler content significantly influenced the flexural strength of the powder-liquid composite $(p<0.01)$. Fig. 1 shows the flexural strength of the composite at different immersion times and with different filler contents. The strength decreased as the immersion time increased, and a significant difference was found between $30 \mathrm{~s}$ and the other two times, $2 \mathrm{~h}$ and $4 \mathrm{~h}(p<0.05)$. The $94 \%$ filler composite had significantly higher strength than the $93 \%$ and $95 \%$ filler composites $(p<0.05)$. Fig. 2 shows the fractured surfaces of the powder-liquid composite specimens. The resin matrix was found closely attached to the particle surfaces and covered the small particles.

The flexural modulus of the powder-liquid composite ranged from 12.2 to 17.6 $\mathrm{GPa}$, whereas that of the 2-paste composite was $11.9 \mathrm{GPa}$. Five of the 18 powderliquid composites had a significantly higher modulus than the 2-paste composite ( $p$ $<0.05)$. Three main factors, 4-META concentration, filler content and immersion time, significantly influenced the flexural modulus of the powder-liquid composite ( $p$ $<0.01)$. Fig. 3 shows the flexural modulus at different 4-META concentrations, immersion times and filler contents. The modulus significantly increased as the 4META concentration decreased from 0.2 to 0.1 , as the immersion time decreased from $2 \mathrm{~h}$ to $30 \mathrm{~s}$, and as the filler content increased from $93 \%$ to $94 \%$.

The working time and setting time of the powder-liquid composite ranged from 2.3 to $13.6 \mathrm{~min}$, and from 4.2 to $20.1 \mathrm{~min}$, respectively. All of the powder-liquid composites fulfilled the requirement of ISO 4049 for resin-based filling materials ${ }^{5)}$ for working time (not less than $90 \mathrm{~s}$ ). Four composites complied with the standard requirement for setting time (not more than $5 \mathrm{~min}$ ). For the 2-paste composite, these times were 9.3 and $13.4 \mathrm{~min}$, respectively. 10 of the 18 powder-liquid composites showed a significantly shorter working time whereas two of them had a significantly longer working time than the 2-paste composite. Both the working time and setting time of the powder-liquid composite were significantly influenced by all main factors $(p<0.01)$ and two interactions; that between 4-META concentration and immersion time $(p<0.05)$ and that between 4-META concentration and filler content $(p<0.01)$. Fig. 4 shows the working time and setting time for different 4-META concentrations, immersion times and filler contents. Both the working time and setting time significantly increased as 4-META concentration increased from 0.1 to 0.2 , as filler content increased from $94 \%$ to $95 \%$, and as immersion time increased from $30 \mathrm{~s}$ to $2 \mathrm{~h}$ at 0.2 ratio of 4-META concentration $(p<0.05)$. A significant correlation was found between the working time and the setting time $(r=0.994)$ and the regression equation was as follows. 
A

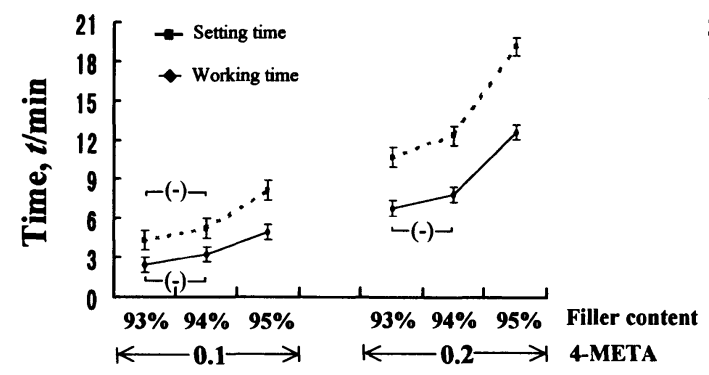

B

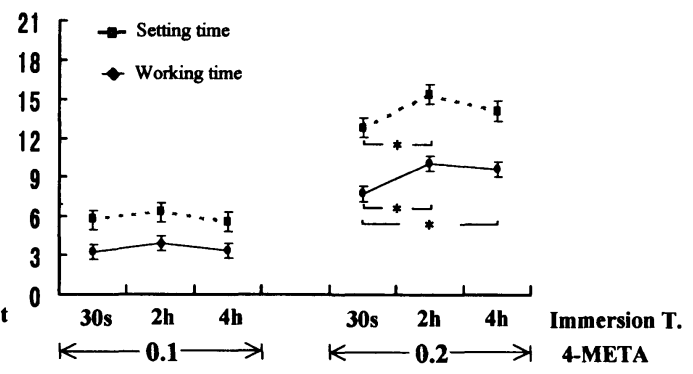

I: $95 \%$ confident interval, ${ }^{*}$ : Significantly different at $\mathrm{P}<0.05, \quad(-)$ : Not significantly different at $\mathrm{P}=0.05$

Tukey's interval : 1.57 for working time, 1.20 for setting time in both figures

Fig. 4 Working time and setting time of the powder-liquid composite, at different filler contents and 4-META concentrations (A) and different immersion times and 4-META concentrations (B).

$\mathbf{A}$

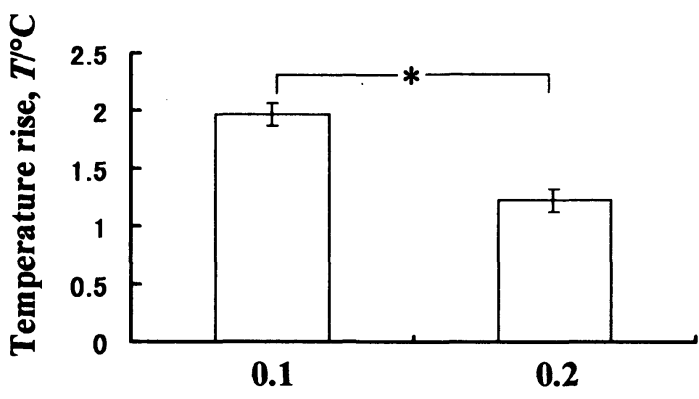

4-META Concentration

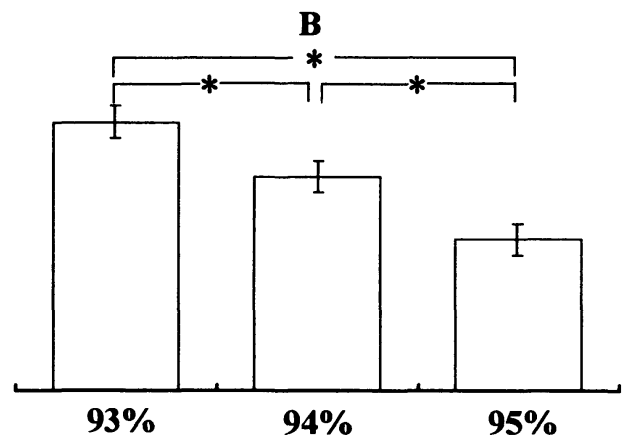

Filler Content

I: 95\% confident interval, * : Significantly different at $\mathrm{P}<0.05$

Tukey's interval : 0.14 for 4-META concentration, 0.21 for filler content

Fig. 5 Temperature rise of the powder-liquid composite, at different 4-META concentrations (A) and different filler contents (B).

$$
t \mathrm{~s}=1.4 t \mathrm{w}+0.90
$$

where $t \mathrm{~s}$ : Setting time of the powder-liquid composite (min)

$t \mathrm{w}$ : Working time of the powder-liquid composite $(\mathrm{min})$

The temperature rise of the powder-liquid composite ranged from 0.8 to $2.7^{\circ} \mathrm{C}$ and that of the 2-paste composite was $1.0^{\circ} \mathrm{C}$. Six of the 9 powder-liquid composites treated at 0.1 ratio of 4-META concentration showed a significantly higher temperature rise, but no significant difference was found between the 2-paste composite and 
any of the powder-liquid composites treated at 0.2 concentration. The temperature rise of the powder-liquid composite was significantly influenced by the 4-META concentration and the filler contents $(p<0.01)$. As shown in Fig. 5 , the temperature rise increased significantly with the decreases of 4-META concentration and filler content $(p<0.05)$. The temperature rise had a significantly negative correlation with working time $(\mathrm{r}=-0.863)$ and setting time $(\mathrm{r}=-0.874)$, and the regression equations were as follows.

$$
\begin{aligned}
& t \mathrm{w}=-5.6 \mathrm{Tr}+15.30 \cdots \cdots(4) \\
& t_{\mathrm{S}}=-8.2 \mathrm{Tr}+23.04 \cdots \cdots(5)
\end{aligned}
$$

where $\operatorname{Tr}$ : Temperature rise of the powder-liquid composite $\left({ }^{\circ} \mathrm{C}\right)$

$t \mathrm{w}$ and $t \mathrm{~s}$ : as above defined

The percent elution of leachable components from the powder-liquid composites ranged from 23.2 to $33.7 \%$ and that from the 2-paste composite was $22.6 \%$ (Table 5). No significant difference in the percent elution was found between the 2-paste and

Table 5 The percent elution of leachable components from the powder-liquid composite and former 2-

\begin{tabular}{|c|c|c|}
\hline \multicolumn{2}{|c|}{ Condition } & $\begin{array}{c}\text { Percent elution } \\
(\%)\end{array}$ \\
\hline \multicolumn{2}{|c|}{ 2-paste composite } & $22.63(2.22)$ \\
\hline \multicolumn{2}{|c|}{ Powder-liquid composite } & \\
\hline Immersion time & Filler content & \\
\hline $30 \mathrm{~s}$ & $\begin{array}{l}94 \% \\
95 \%\end{array}$ & $23.72(1.13)$ \\
\hline \multirow{2}{*}{$2 \mathrm{~h}$} & $94 \%$ & $23.19(4.40)$ \\
\hline & $95 \%$ & $33.74(4.34)$ \\
\hline \multirow[t]{2}{*}{$4 \mathrm{~h}$} & $94 \%$ & $23.97(3.61)$ \\
\hline & $95 \%$ & $28.43(5.59)$ \\
\hline \multicolumn{2}{|c|}{$\begin{array}{c}\text { Tukey's Interval } \\
\text { for one-way ANOVA }\end{array}$} & 12.33 \\
\hline
\end{tabular}
paste system

$\mathrm{SD}$ in parentheses

No significant difference was found among all means

Table 6 The results of two-way ANOVA for the percent elution of leachable components from the powder-liquid composite

\begin{tabular}{lrccrl}
\hline \multicolumn{1}{c}{ Factors } & df & Sum of Squares & Mean Squares & F value & P value \\
\hline A (Immersion time) & 2 & 19.445 & 9.723 & 0.442 & 0.653 \\
B (Filler content) & 1 & 293.546 & 293.546 & 13.347 & $0.003^{* *}$ \\
A $\times$ B & 2 & 30.710 & 15.355 & 0.698 & 0.517 \\
Residual & 12 & 263.913 & 21.993 & & \\
Total & 17 & 607.614 & & & \\
\hline
\end{tabular}




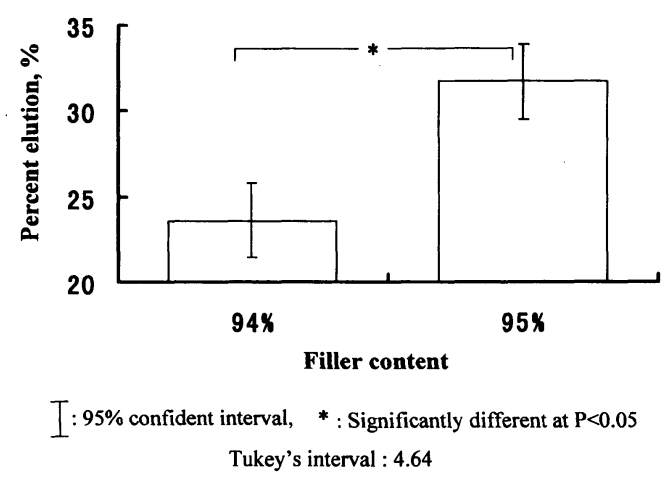

Fig. 6 Percent elution of the powder-liquid composite.

powder-liquid composites. Table 6 shows the result of two-way ANOVA for the percent of elution from the powder-liquid composite. The percent elution was significantly influenced by filler content $(p<0.01)$. As shown in Fig. 6, the percent elution significantly increased as filler content increased. A significant correlation was found between the percent elution and the flexural strength of the powder-liquid composite $(\mathrm{r}=-0.851)$. The percent elution also had a significant correlation with working time $(r=0.908)$, setting time $(r=0.951)$ and temperature rise $(r=-0.957)$. The regression equations between the percent elution and three properties, the flexural strength, working time and setting time, were as follows.

$$
\begin{array}{ll}
\mathrm{FS} & =-0.7 \mathrm{PE}+96.04 \\
\mathrm{PE}=4.2 t \mathrm{w}+10.73 & \cdots \cdot(6) \\
\mathrm{PE}=2.8 t \mathrm{~s}+9.20 & \cdots \cdots(8) \\
\mathrm{PE}=-11.8 \mathrm{Tr}+48.05 & \cdots \cdots(9)
\end{array}
$$

where FS: Flexural strength of the powder-liquid composite $(\mathrm{MPa})$

PE: Percent elution of the powder-liquid composite (\%)

$\mathrm{Tr}, t \mathrm{w}$ and $t \mathrm{~s}$ : as above defined

\section{DISCUSSION}

In the previous study ${ }^{3,4}$, the metal-resin composites were experimentally prepared in 2paste form. As mentioned in the introduction, several problems might have been generated in the 2-paste system due to the reactivity of the alloy particles and the reaction between 4-META and DMPT, which may have resulted in the low strength of these composites. To minimize these problems and to further improve the strength of the composite, a powder-liquid system was developed in the present study. The 4META-treated particles were separated from the UDMA monomer containing DMPT in order to prevent the early polymerization of UDMA and the reaction between DMPT and 4-META. The results of the flexural tests showed that many of the 
prepared powder-liquid composites had significantly higher strength than the 2-paste composite, and the highest value was about $43 \%$ more. This result indicates that the powder-liquid system is effective for improving the mechanical properties of the metal-resin composite consisting of $\mathrm{Ag}$-Sn filler particles and 4-META coupling agent. Generally, the flexural strength of a composite depends upon the filler content $t^{9,10)}$, the rate of conversion ${ }^{11}$, the degree of polymerization ${ }^{12)}$ and the bond between the filler particles and the resin matrix ${ }^{3,4,10}$. The increase in flexural strength of the powderliquid composite may be related to these factors.

Five of the six powder-liquid composites containing $93 \%$ filler showed significantly higher strength than the 2-paste composite which also contained $93 \%$ filler (Table 4). This result may indicate that the filler content may not have been the reason for the increase in flexural strength of the powder-liquid composite. Although we expected a higher rate of conversion in the powder-liquid system than in the 2-paste system, no significant difference was found in the percent elution between powderliquid and 2-paste composites, which indicates no difference in the rate of conversion between these two types of composite. This result suggests that the increase in the flexural strength of the powder-liquid composite was not related to the rate of conversion of the resin matrix. Therefore, the other two factors, the degree of polymerization and the bond between filler particles and resin matrix, could be responsible for the increase in the flexural strength. One of the main differences between the previous 2-paste system and the present powder-liquid system is the distribution of BPO. The BPO in the powder-liquid system is only available on the surface on the filler particles whereas that in the 2-paste paste system is distributed in the monomer of one paste. This difference may be related to the propagation of polymer chains and consequently to the degree of polymerization in the powder-liquid system, resulting in the increase in the flexural strength. This should be further investigated in a future study. With respect to the bond between filler particles and resin matrix, Fig. 2 showed a similar attachment of the resin matrix to the metal particles to that previously reported ${ }^{4)}$, indicating that the bond between the filler particles and the resin matrix is different between the two systems. A further study, however, is necessary to prove the absence of differences in the bond between these two systems since SEM photographs cannot show differences in the structure.

For the powder-liquid composite, the flexural strength was significantly influenced by two factors, immersion time and filler content. It decreased as the immersion time increased (Fig. 1A). According to the studies by Miyagawa et al. ${ }^{6,7)}$, UDMA polymerizes under the existence of Ag-Sn particles, 4-META and BPO. This result suggests that not only UDMA but also 4-META has polymerized. Polymerization of the 4-META might not have been induced at $30 \mathrm{~s}$ immersion but induced at longer immersion such as $2 \mathrm{~h}$ and $4 \mathrm{~h}$. And thus the co-polymerization between 4-META and UDMA was not well achieved at longer immersion time, resulting in the lower strength of the composite. As shown in Fig. 1B, a higher flexural strength was obtained at $94 \%$ filler content regardless of 4 -META concentration and immersion time. Several studies ${ }^{9,10}$ have shown that the strength of composites increases with the 
increase of the filler content. This was also found in the present study up to $94 \%$. The strength, however, significantly decreased at $95 \%$. This may be related to the lower rate of conversion of the 95\% composite. As shown in Fig. 6, the percent elution at $95 \%$ filler content was significantly higher than that at $94 \%$, which indicates lower rate of conversion, resulting in the lower strength of $95 \%$ composite. As well as the result of the temperature rise in Fig. 5B, 95\% filler content clearly showed the significantly lower temperature rise than that at $94 \%$, which may be related to the lower rate of conversion ${ }^{13,14)}$. Ferracane et $a l^{9)}$ found that the rate of conversion increases with the increase of filler content up to certain filler content and then decrease as the filler content increases. This result is in agreement with that of the present study. The reason for the decrease in the rate of conversion should be further investigated.

As discussed before, percent elution was not the reason for the increase in the flexural strength of the powder-liquid composites when compared with the 2-paste composites. Among powder-liquid composites, however, a significant correlation was found between flexural strength and percent elution. This indicates that the strength of the powder-liquid composite was influenced by the rate of conversion, which is in agreement with the previous studies ${ }^{11,12)}$.

The flexural modulus of the powder-liquid composites was significantly influenced by three main factors; 4-META concentration, immersion time and filler content. In composite materials, the filler particles are distributed in the matrix and work to restrict the deformation of the matrix. Thus, the modulus of the composite is dependent on that of the filler and its content $t^{10,15,16)}$. The results of this study also show these roles of the filler for the flexural modulus. The higher concentration of 4META and longer immersion time significantly decreased the flexural modulus of the composite. This can be explained by the increase of 4-META layer at the higher 4META concentration and the longer immersion time in the set composite. If the whole amount of 4-META was consumed to cover the filler particles, the average percentage of total resin matrix including 4-META was calculated to be 5.89 mass\% (4META: 0.93 mass\%) and 6.77 mass\% (4-META: 1.84 mass\%) at 0.1 and 0.2 ratio of 4-META concentrations, respectively. It is very probable that the composite treated at the higher concentration and for a longer immersion time contains more resin matrix, including 4-META, resulting in the lower flexural modulus.

Not only the mechanical properties but also the working and setting time were improved by the powder-liquid system. The working time and setting time of the 2paste composite were 9.3 and $13.4 \mathrm{~min}$, respectively. These may be too long for clinical use. On the other hand, some of the powder-liquid composites fulfilled the requirements for working time (not less than $90 \mathrm{~s}$ ) and setting time (not more than $5 \mathrm{~min}$ ) specified in ISO 40495). These composites appear to have appropriate working and setting times for practical use. It should be noted that the working time and setting time of one composite which had the highest flexural strength $(91.8 \mathrm{MPa})$ were $3.0 \mathrm{~min}$ and $5.2 \mathrm{~min}$, respectively. Although this setting time was slightly longer than the ISO requirement, this composite can be applied for posterior restorations. 
Although the results of the present study have indicated the efficacy of the powderliquid system, it seems that the rate of the polymerization is still the same as the 2paste system. Therefore, a further study is necessary to improve the rate of conversion of the metal-resin composite. In addition, the other properties such as wear resistance, dimensional change and biocompatibility should be further investigated before clinical use of this material.

A significant correlation was found among the percent elution, working time, setting time and temperature rise. These correlations indicate that a shorter working time and/or setting time results in a higher temperature rise and a lower rate of conversion of the composite. Fundamentally, the working time and setting time can be prolonged or shortened by the temperature ${ }^{17)}$, the ratio of the redox initiator ${ }^{18)}$ and addition of an accelerator or retarder ${ }^{18)}$. Therefore, it should be noted that the correlations related to working time and setting time can stand when these conditions are fixed as in the present study.

In a preliminary experiment, the residual monomer content in a set composite was measured using gas chromatography to investigate the rate of conversion of the powder-liquid composite in relation to its properties. The measured amount, however, was only $0.2-0.3 \%$ which was far below the eluted amount (about $20-30 \%$ ) using a Soxhlet extraction device. It was noted in this experiment that the difference between amounts of the measured monomer and the eluted component might have been due to polymerization of the extracted monomer. This was suggested by the production of a film-like substance in the extracted liquid. It is very probable that the surfaces of the metal particles are exposed by crushing of the composite specimen and are activated at high temperature for extraction, resulting in polymerization of the extracted monomer. For this reason, gas chromatography measurement of the residual monomer was not adopted but the eluted component was measured to investigate the effect of the rate of conversion on the properties of the powder-liquid composite.

The residual monomer in this study was evaluated by extraction of the components eluted from the whole composite mass. The Soxhlet extraction procedure was adopted to produce an aggressive environment for extraction. Acetone was selected as the solvent for extraction based on two reasons. First, acetone has a solubility parameter of $1.9 \times 10^{4}\left(\mathrm{~J} / \mathrm{m}^{3}\right)^{1 / 2}{ }^{19)}$ which is suitable to dissolve base polymers of dental composites $^{20)}$. Second, acetone itself has a high ability to soften and swell the polymer network to easily release the residual monomer which is entrapped in the network. This ability is higher than water, methanol, ethanol or their combination ${ }^{19)}$, which were used in the past studies ${ }^{20-28)}$ The percent elution ranged from 23.2 to $33.7 \%$ of the initial monomer. These values were slightly lower than those of previous studies $^{9,29-31)}$. Tanaka et $a$. $^{24)}$ studied the elutable components of conventional dental composites in water and concluded that the minor component, mainly TEGDMA, dissolved into water, but most residual monomers remained in the set composite. Another study by Ferracane et $a l .^{28)}$ has shown that most of the minor component of the composite can dissolve into water within $24 \mathrm{~h}$. In this study, the composite was immersed for $24 \mathrm{~h}$ before the flexural test and thus some of the elutable component 
could have dissolved into the water, resulting in the lower value of the percent elution.

\section{CONCLUSION}

The highest flexural strength of the powder-liquid composite was $91.8 \mathrm{Mpa}$, which was higher than the 2-paste composite $(64.0 \mathrm{MPa})$ by about $43 \%$. This was achieved at a 0.1 ratio of 4 -META concentration, $30 \mathrm{~s}$ immersion time and $94 \%$ filler content. The working time and setting time ranged between 2.3-13.6 min and 4.2-20.1 $\mathrm{min}$, respectively and those of the highest strength composite were 3.0 and 5.2, respectively. These results indicate that the powder-liquid system is effective for improving the properties of the metal-resin composite.

The flexural strength of the powder-liquid composite increased significantly as the filler content increased from 93 to $94 \%$ and as the immersion time decreased from $2 \mathrm{~h}$ to $30 \mathrm{~s}$. A significant correlation was found between the flexural strength and percent elution of leachable components from the powder-liquid composite, indicating that the rate of conversion is one of the factors responsible for the strength of the powder-liquid composite but not the reason for the improvement of this composite. The flexural modulus increased significantly as the filler content increased from 93 to $94 \%$, as the immersion time decreased from $2 \mathrm{~h}$ to $30 \mathrm{~s}$, and as the 4-META concentration decreased from 0.2 to 0.1 .

The working time and setting time significantly increased as the filler content increased from 93 to $95 \%$, as the immersion time increased from $30 \mathrm{~s}$ to $2 \mathrm{~h}$, and as the 4-META concentration increased from 0.1 to 0.2 . The temperature rise during setting ranged between 0.8 and $2.4^{\circ} \mathrm{C}$. It decreased significantly as the 4-META concentration increased from 0.1 to 0.2 and as the filler content increased from 93 to $95 \%$. A significant correlation was found among these three parameters as well as between the three parameters and percent elution of leachable components from the powder-liquid composite under the test conditions of this study.

\section{ACKNOWLEDGMENT}

The authors acknowledge Dr.Chatcharee Suchatlampong and Mr.Apiwat Rittapai, Mahidol University, Thailand, for providing the Ag-Sn alloy particles, and Sun Medical Co., Ltd. for providing the 4-META.

\section{REFERENCES}

1) Hirano, S. and Hirasawa, T.: Soft magnetic stainless steel powder filled composites, Dent Mater J 12 (Special Issue 22) : 142-143, 1993.

2) Hirano, S., Yasukawa, H., Nomoto, R., Moriyama, K. and Hirasawa, T.: Properties of Magnetically Attractive Experimental Resin Composites, Dent Mater J 15(2) : 91-97, 1996.

3) Kakuta, K., Urapepon, S., Miyagawa, Y., Ogura, H., Suchatlampong, C. and Rittapai, A.: Development of metal-resin composite restorative material; Experimental composite containing silver-tin alloy as filler, Dent Mater $J$ 18(1):1-10, 1999. 
4) Urapepon, S., Kakuta, K., Miyagawa, Y., Ogura, H., Suchatlampong, C. and Rittapai, A.: Development of metal-resin composite restorative material; Part 2 Effects of acid and heat treatment of silver-tin filler particles on the flexural properties of the metal-resin composite (will publish in Dent Mater $J$ 18(2), 1999)

5) International organization for standardization, Draft international standard ISO/DIS 4049; Dentistry-Polymer-based filling, restorative and luting materials, ISO, 1998.

6) Miyagawa, Y., Urapepon, S., Ogura, H. and Honda, N.: New initiation system for resin polymerization with metal, Transactions of Third international congress on dental materials, Abstract no P-128: 258, November 1997.

7) Miyagawa, Y., Urapepon, S., Ogura, H. and Honda, N.: Setting of UDMA containing BPO by metal powder and 4-META, $J J$ Dent Mater 16 (Special issue 30): Abstract no P-28, 67, 1997 (in Japanese)

8) Jones, M. J.: Organic chemistry, W. W. Norton \& Company, USA, 1997, pp.1003-1069.

9) Ferracane, J. L., Berge, H.X. and Condon, J. R.: In vitro aging of dental composites in water- Effect of degree of conversion, filler volume, and filler/matrix coupling, $J$ Biomed Mater Res $42: 465-472,1998$.

10) Braem, M., Finger, W., Van Doren, V.E., Lambrechts, P. and Vanherle, G.: Mechanical properties and filler fraction on dental composites, Dent Mater $5: 346-349,1989$.

11) Peutzfeldt, A.: Quantity of remaining double bonds of diacetyl-comtaining resin, $J$ Dent Res 73(2) : 511-515, 1994.

12) Yoshida, K., Greener, E. H.: Effects of two amine reducing agents on the degree of conversion and physical properties of an unfilled light-cured resin, Dent Mater $9: 246-251$, 1993.

13) Phillips, R.W.: Skinner's Science of dental materials, $9^{\text {th }}$ edition, W. B. Saunders company, USA, 1991, pp.177-213.

14) Ban, S. and Hasegawa, J.: Heat of polymerization of dimethacrylate monomers investigated by isothermal DSC measurement, Dent Mater $J$ 3(1):85-92, 1984.

15) Hayasi, T.: Fukugou zairyou kougaku (Composite materials engineering), 1st ed., Nikkagiren Publishing Co., Tokyo, 1971, pp.29. (in Japanese)

16) Jones, D. W. and Rizkalla, A.S.: Characterization of experimental composite biomaterials, J Biomed Mat Res $33: 89-100,1996$.

17) Odian, G.: Principles of polymerization, $3^{\text {rd }}$ ed., John Wiley \& Sons Ltd., Singapore, 1991, pp.356-449.

18) Asmussen, E.: Setting time of composite restorative resin vs. content of amine, peroxide and inhibitor, Acta Odontol Scand 39 : 291-294, 1981.

19) Burke, J.: Solubility parameters-Theory and application, The AIC book and paper group annual $3: 13-58,1984$.

20) Wu, W. and McKinney, J. E.: Influence of chemicals on wear of dental composites, $J$ Dent Res 61(10): 1180-1183, 1982.

21) Inoue, K. and Hayashi, I.: Residual monomer (Bis-GMA) of composite resin, $J$ Oral Rehab 9 : 493-497, 1982.

22) Rueggeberg, F. A. and Craig, R. G.: Correlation of parameters used to estimate monomer conversion in a light-cured composite, J Dent Res 67 : 932-937, 1989.

23) Rathburn, M. A., Craig, R. G., Hanks, C. T. and Fulisko, F. E.: Cytotoxicity of a BisGMA dental composite before and after leaching in organic solvents, $J$ Biomed Mat Res $25:$ 443-457, 1991.

24) Tanaka, K., Taira, M., Shintani, H., Wakasa, K. and Yamaki, M.: Residual monomers (TEGDMA and Bis-GMA) of a set visible-light-cured dental composite resin when immersed in water, J Oral Rehab $18: 353-362,1991$.

25) Thomson, L. R., Miller, E. G. and Bowles, W. H.: Leaching of unpolymerized materials from orthodontic bonding resin, J Dent Res 61 : 989-992, 1982.

26) Ferracane, J. L.: Elution of leachable components from composite, $J$ Oral Rehab 21 : 441$452,1994$. 
27) Spahl, W., Budzikiewicz, H. and Geurtsen, W.: Determination of leachable components from four commercial dental composites by gas and liquid chromatography/mass spectrometry, J Dent 26(2): 137-145, 1998.

28) Ferracane, J. L. and Condon, J. R.: Rate of leachable components from composite, Dent Mater 6 : 282-287, 1990.

29) Ruyter, I. E. and Svendsen, S. A.: Remaining methacrylate groups in composite restorative materials, Acta Odontol Scan $36: 75-82,1977$.

30) Asmussen, E.: Factors effecting the quantity of remaining double bonds in restorative rein polymers, $J$ Dent Res $90: 490-496,1982$.

31) Ruyter, I. E. and Oysaed, H.: Composites for use in posterior teeth: Composition and conversion, J Biomed Mat Res 21 : 11-13, 1987. 